\title{
INVESTIGACIONES
}

\section{La representación de las mujeres prehistóricas en los textos escolares de Historia, Geografía y Ciencias Sociales en Chile (2010-2018)}

\author{
The representation of prehistoric women in the textbooks \\ of History, Geography and Social Sciences in Chile (2010-2018)
}

\author{
Oscar Andrés Marín San Martín \\ Máster en Prehistoria, Antigüedad y Edad Media. Universidad Autónoma de Barcelona, España. \\ oscarmarinsm@gmail.com
}

\section{RESUMEN}

La prehistoria es un período donde convive la historia y la ciencia, pero también el mito y la ficción, siendo necesario acudir a su estudio para conocer el discurso histórico que hemos heredado. Así, resulta relevante atender a los objetos y sujetos prehistóricos que se han transmitido o se siguen transmitiendo en diversos modelos de enseñanza. Una forma de hacerlo es a través del estudio de los textos escolares, ya que éstos se configuran, aún en la era digital, como los artefactos didácticos que mantienen mayor vigencia en la difusión de modelos de enseñanza. En esta ocasión se estudian los manuales de Historia, Geografía y Ciencias Sociales entre 2010 y 2018 en Chile, identificando, principalmente, cómo se exhiben a las mujeres prehistóricas en los estudiantes de $7 \mathrm{mo}$ básico. Para esto, se han considerado tanto los discursos como las imágenes de los manuales.

Palabras claves: prehistoria, arqueología, educación.

\begin{abstract}
Prehistory is a period where history and science coexist, but also myth and fiction, being necessary to appeal to its study to know the historical discourse that we have inherited. Thus, it is relevant to heed to prehistoric objects and subjects that have been transmitted or continue to be transmitted in various teaching models. One way of doing this is through the study of school texts, since these are configured, even in the digital age, as the didactic artifacts that maintain greater validity in the dissemination of teaching models. In this occasion the manuals of History, Geography and Social Sciences are studied between 2010 and 2018 in Chile, identifying, mainly, how prehistoric women are exhibited in the 7 th grade students. For this, both the discourses and the images of the manuals have been considered.
\end{abstract}

Key words: prehistory, archaeology, education. 


\section{INTRODUCCIÓN}

En el siglo XX diversos enfoques historiográficos han propiciado que los objetos y sujetos históricos de estudio se hayan reestructurado, de forma que el discurso que hemos heredado como verdadero esté constantemente cuestionándose. Por ejemplo, con las oleadas del movimiento feminista y los estudios de género se estableció un escenario teórico que ha discutido el papel de las mujeres como sujetos históricos. Diversas ciencias sociales y campos del conocimiento afines a las humanidades han tomado las perspectivas revisionistas y las incluyeron en sus investigaciones. Este fue el caso de la arqueología, en donde las escuelas norteamericanas y escandinavas fueron pioneras en incluir que el discurso presentista había configurado, bajo prismas androcéntricos y patriarcales, una representación del objeto de estudio meramente masculino, en donde las mujeres no presentaban un papel activo en el desarrollo de la humanidad. Se criticó la sumisión, la pasividad, la domesticación, la limitación espacial y la subyugación de las mujeres en los discursos provenientes de la academia, los que, de alguna u otra manera, son usados para la explicación de los fenómenos sociales contemporáneos. Es relevante abarcar este tipo de estudio ya que "desde la aparición [...] de la prehistoria como campo específico de investigación en el marco de publicación de la teoría evolucionista de Darwin y del desarrollo metodológico de la arqueología, nuestra cultura la concibe como el lugar de nuestros orígenes que explica y justifica ciertos comportamientos actuales" (González, 2009, p. 92).

De esta manera, se ha construido un "imaginario social de la mujer prehistórica" (González, 2012, p. 4) que ha trascendido a la academia, instaurándose, entre otros medios de comunicación, en museos (imagen 1), periódicos (imagen 2), películas (imagen 3) o textos escolares (imagen 4), siendo modelos de enseñanza a partir de prototipos y esquemas determinados. Una de las maneras de acercarnos a la actualidad de esta enseñanza y saber cómo se presenta(n) su(s) rol(es) como sujetos históricos es a través de los manuales escolares, los cuales, amparados en la educación reglada y sistematizados por el currículum nacional, disponen de diversos elementos que establecen, por medio de una ideología de enseñanza, una modelización preconcebida que es aplicada, a través de distintas vías metodológicas, en la trayectoria formativa de los estudiantes. Los textos escolares son uno de los elementos pedagógicos que se han mantenido vigentes aun cuando la era digital domina la actualidad. Por consiguiente, a continuación, se analiza el caso de las mujeres prehistóricas en el discurso y la representación figurativa que están incluidos en los textos escolares de Historia, Geografía y Ciencias Sociales (de ahora en adelante HGyCS) de 7mo básico en Chile, entre los años 2010 y 2018. 
Estudios Pedagógicos XLVI, N $1:$ 7-31, 2020 LA REPRESENTACIÓN DE LAS MUJERES PREHISTÓRICAS EN LOS TEXTOS ESCOLARES DE HISTORIA, GEOGRAFÍA Y CIENCIAS SOCIALES EN CHILE (2010-2018)

Imagen 1: Mujer moliendo granos.

Museo Arqueológico Nacional, Madrid, España (Archivo personal).

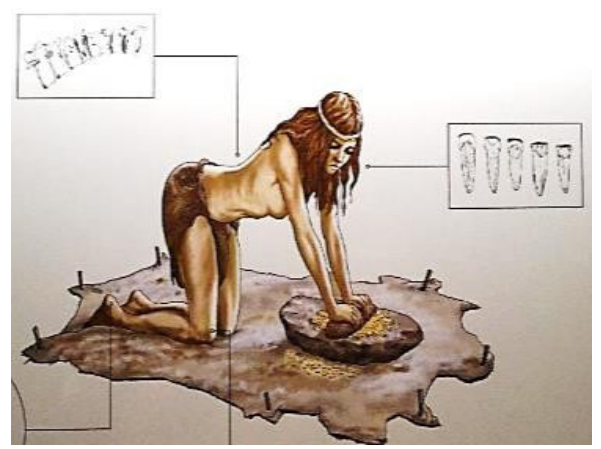

Imagen 2: Ilustración de noticia titulada "Barcelona se alarga por la prehistoria" aparecida el 12 de marzo de 2009 en el diario La Vanguardia, en González, 2009, p. 96.

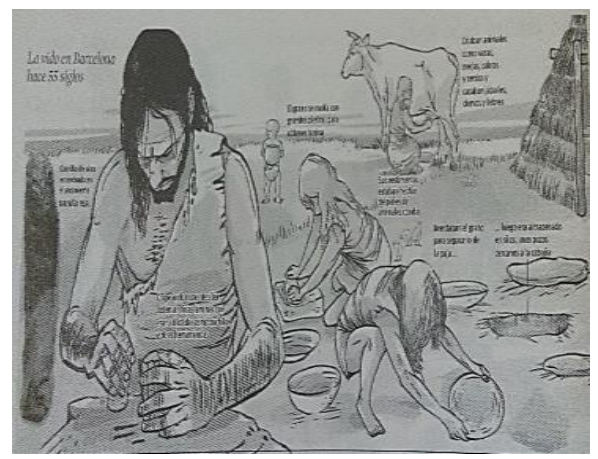

Imagen 3: Ilustración de texto escolar de 7mo básico de HGyCS, Editorial SM Chile, 2016-2018, p. 15.

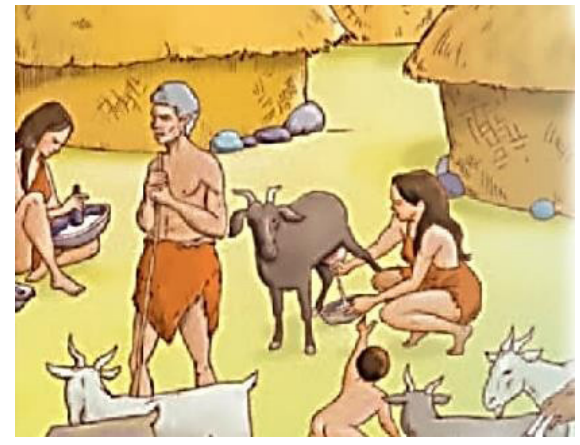



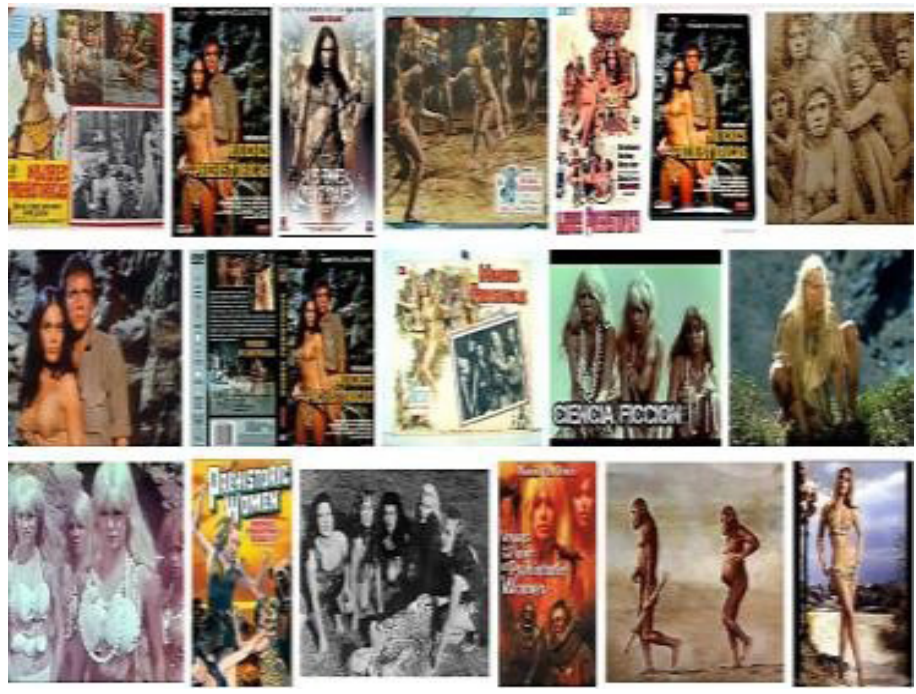

\section{ARQUEOLOGÍA Y EL REVISIONISMO SOBRE LAS MUJERES}

"Están allí, pintadas en las paredes y en los techos de las cavernas. Estas figuras, bisontes, alces, osos, caballos, águilas, mujeres, hombres, no tienen edad. Han nacido hace miles y miles de años, pero nacen de nuevo cada vez que alguien las mira.

¿Cómo pudieron ellos, nuestros remotos abuelos, pintar de tan delicada manera? ¿Cómo pudieron ellos, esos brutos que a mano limpia peleaban contra las bestias, crear figuras tan llenas de gracia? ¿Cómo pudieron ellos dibujar esas líneas volanderas que escapan de la roca y se van al aire? ¿Cómo pudieron ellos...? ¿O eran ellas?”

(Galeano, 2008, p. 8)

El largo camino que ha transitado la humanidad ha sido un trayecto recorrido y compartido por hombres y mujeres, ya que la historia, en cuanto obra humana, es y ha sido colectiva (González, 2006, p. 16). Pero ¿existe realmente tal protagonismo equitativo en el discurso contemporáneo?

Los cambios metodológicos e historiográficos realizados desde el primer tercio del siglo XX propiciaron el establecimiento de nuevos enfoques bajo los cuales entender y hacer historia (Burke, 1996, p. 13). Con las distintas oleadas feministas y las investigaciones a partir de los estudios de género, se establecieron los revisionismos suficientes para que la historia, y otras ciencias o disciplinas sociales, adoptaran nuevos enfoques hacia las mujeres en cuanto sujetos históricos (Sánchez, 2000, p. 499). De acuerdo con Scott, desde la década de los 60' las activistas feministas solicitaron una historia que proporcionara explicaciones de la opresión y pruebas de la actividad de las mujeres en la historia, escenario que pronto 
pasó de la esfera política a una multiplicidad de campos, permitiendo una documentación de todos los aspectos de la vida de las mujeres en el pasado (en Burke, 1996, p. 60). Así, surgió un campo de estudio cuando las mujeres "sintieron la necesidad de explicarse a sí mismas acudiendo a su pasado y a su genealogía, y que continúa alimentándose en la actualidad de la reflexión sobre su identidad, sus experiencias, sobre las contradicciones que les producen los modos de verse representadas [...]" (Flecha, 2004, p. 22), que en palabras de la historiadora Kelly significaba "no sólo devolver las mujeres a la historia, sino devolver la historia a las mujeres" (en Flecha, 2004, p. 22). No obstante, tales revisionismos no debían sólo consistir en una historia referida a lo "privado" o "doméstico" de las mujeres, sino que debía asumir las cuestiones de cómo las mujeres habían vivido en familia, con el trabajo, con la sexualidad, la democracia, el ámbito público, entre otras (Sánchez, 2000, p. $501)$, tanto en el presente como en tiempos remotos, incluso bajo escenarios culturales de la prehistoria.

De este modo, y con protagonismo en las áreas de la psicología, la sociología y la antropología, se asumió un discurso en las investigaciones que criticaba el establecimiento de un relato androcéntrico heredado como verdad histórica y que se ha generalizado bajo consignas de historia universal -0 , para este caso, de prehistoria universal-, legitimándose una cultura de poder del hombre sobre la mujer (González, 2006, p. 18). Así, por ejemplo, los trabajos -por nombrar algunos- en la década de los 70' de Draper sobre las mujeres !kung, o de Slocum sobre los vacíos de la tesis cazadora como actividad meramente masculina y de subsistencia, planteaban nuevos modelos para pensar el pasado humano desde la antropología física y la primatología (Vila, 2011, p. 21). Más tarde, en la década de los 80', y a partir del impulso de la escuela arqueológica norteamericana y de la noreuropea, se desarrolló este revisionismo histórico desde la propia arqueología (Sánchez, 2000; González, 2006; Alarcón, 2010; Vila, 2011; Zurro, 2011) que más tarde repercutiría en las escuelas arqueológicas del resto de Europa y América (Romero y Sanz, 2009, p. 59), desvelando con esto "concepciones normativas del pasado que reflejaban los valores ideológicos de los propios investigadores, desfavorecían a las mujeres y legitimaban la ideología de género dominante" (Montón, 2014, p. 242). De este modo, el género, como categoría analítica, se incorporó, aunque más tarde que en otros campos de las ciencias sociales, a la investigación arqueológica -como por ejemplo con los trabajos de Conkey, Spector o Tringham-, posibilitando la interpretación cultural e histórica al margen de la diferencia sexual, separándose lo biológico de lo sociocultural (2014, p. 243).

Bajo la concepción de género que surgió con el movimiento feminista, según Scott, debe entenderse una "categoría de análisis histórico que nos ayude a descubrir cómo los espacios, trabajos, valores y comportamientos de uno y otro género son un producto histórico" (en Sánchez, 2000, p. 503), aunque, también, es necesario entender el género más allá de la dualidad sexual y concebir en ello un sistema de relaciones, es decir, el estudio no en sí de los géneros separados sino que las relaciones que se establecen entre ellos y ellas a modo de analizar tal organización social en la prehistoria e historia (2000, p. 503).

Así, Montón ha establecido el concepto de "arqueologías engeneradas" para referirse a "todas aquellas arqueologías que explícitamente problematizan el sexo, el género y/o sexualidad en las interpretaciones del pasado y/o en el ejercicio de la profesión" (2014, p. 243). A su vez, Lozano apunta al concepto de "tópico androcéntrico" para referirse a que éste, entendido como "idea distorsionada, estereotipo que contiene lugares comunes, 
argumentos poco rigurosos pero que se repiten con asiduidad y se infiltran en la parte menos noble delideario colectivo" (Lozano, 2011, p. 19) ha puesto al hombre como medida de todas las cosas. Y ha sido así, siguiendo a Lozano, desde la institución universitaria en donde la "comunidad científica, consciente o inconscientemente, lo ha diseminado en sus discursos académicos", llegando posteriormente al público general (2011, p. 19).

Sánchez indica que la invisibilización de la mujer como sujeto histórico no se debe al hallazgo de menos restos arqueológicos de mujeres prehistóricas que de hombres, sino que la cuestión radica en que "el problema se encontraba en los presupuestos teóricos e ideológicos, en las ideas previas de los investigadores e investigadoras que recopilaban y seleccionaban aquello que consideraban relevante para la construcción de la historia" (2000, p. 496).

A comienzos de la década de los 80', Angela Davis se centraba en la figura de la "ama de casa", en donde indicaba que "el trabajo doméstico se estima que consume entre tres y cuatro mil horas anuales del tiempo de una ama de casa media", acto que, a su vez, se lo cataloga como "invisible, repetitivo, extenuante, improductivo, nada creativo" (2005, p. 221). Esta consideración también fue tomada por la arqueología, estableciéndose el estudio de las "actividades de mantenimiento" a modo de reivindicar el lugar de la mujer prehistórica en la supervivencia de la comunidad (González, 2006, 2009; Alarcón, 2010; Montón, 2014). Éstas engloban, incluso más allá del hogar, "el conjunto de prácticas relativas al mantenimiento y al cuidado de cada uno de los miembros de una comunidad", destacándose todas las prácticas relacionadas con el reemplazo generacional. De acuerdo con lo anterior, estos trabajos incluyen la preparación de alimentos, su distribución y consumo, la deposición o el almacenamiento; además de implicar el cuidado de los miembros infantiles de la comunidad y de aquellos individuos incapaces de cuidar de sí mismos por razones de edad o enfermedad (Picazo en Alarcón, 2010, p. 196). De este modo, bajo el abrigo de estas actividades, se ha realizado un aporte teórico, metodológico y de práctica profesional en la arqueología, desde donde el análisis de la escala local, los espacios del día a día, "han dejado de ser espacios neutros que reflejan únicamente cambios acaecidos en otros espacios sociales para convertirse en lugares vitales de las dinámicas sociohistóricas" (Montón, 2014, p. 244), lo que se relaciona directamente con la escala de tiempo del acontecimiento braudeliano o la microhistoria ginzburgiana, en donde "la microescala, en el nivel de la unidad doméstica (household) o del acontecimiento, donde las prácticas cotidianas, el espacio estructurado, el saber y la producción locales [...] resultan accesibles" (Conkey en González, 2006, p. 18). La pretensión del posicionamiento en la discusión arqueológica y prehistórica de las actividades de mantenimiento es indicar que éstas fueron tan relevantes como las de caza, recolección, producción y muchas otras, por cuanto significaron la estabilidad, cohesión y permanencia del grupo en el tiempo. Con ello no se pretende justificar que hayan sido los hombres los únicos que debieron ejecutar acciones vinculadas con la caza, la recolección, la producción u otras, puesto que es tan probable que tales labores hubiesen sido realizadas por ellos como por ellas. Lo que ha ocurrido es que, por extrapolación etnográfica marcadas por experiencias particularistas o, casi siempre, por el apriorismo personal y profesional de los que patentan la verdad histórica, las explicaciones entorno a la vida tecnológica -asociada a inventiva XY-se han superpuesto a las vinculadas con el mantenimiento de las relaciones humanas, de manera que debiera atenderse, de mejor manera, a que "ambos campos son cuanto menos, igual de importantes para proveer de los sistemas necesarios que aseguren la supervivencia 
de los grupos" (Juliano en Alarcón, 2010, p. 199). Por este motivo, la negación de la mujer como sujeto histórico nace a partir de los esquemas culturales del presente, lo que Lozano denomina como "distorsión de proyección de ideas actualistas" sobre la división sexual del trabajo y los papeles desempañados por los sexos en la prehistoria (Lozano, 2011, p. 20).

Una manera de observar las repercusiones de las investigaciones académicas y la producción científica en el área de la arqueología es a través de la educación formal, específicamente, en el material con el que los estudiantes acceden a gran parte de su conocimiento obligatorio. Es por ello que, a continuación, se considera la relevancia del texto escolar como medio de estudio a modo de observar la representación de las mujeres dentro de la formación de los escolares chilenos.

\section{EL TEXTO ESCOLAR Y EL CURRÍCULUM EDUCACIONAL}

\subsection{EL TEXTO ESCOLAR}

Desde un punto de vista pedagógico y metodológico, se ha destacado el papel del texto escolar como medio de trasmisión del currículo con el que los docentes pueden planificar clases y enseñanzas, y como instrumento didáctico altamente utilizado en clases (Eyzaguirre y Fontaine, 1997; López, 2000; Bayón, Pupio y Simón, 2009; Abril y Cuenca, 2016). Por otra parte, se ha considerado a los textos escolares como medios ideológicos, en cuanto materiales curriculares con un rol directo en la formación de profesores y, sobre todo, estudiantes, moldeando la cultura de una sociedad -sobre todo el manual de HGyCS-, trascendiendo en la construcción y transmisión de valores y de un saber condicionado dentro la educación formal (Gordones, 2008; Fernández, 2010; Lewkowicz y Rodríguez, 2015). Habría un control por parte de los grupos de poder que rompen con la neutralidad del discurso que se quiere transmitir, creando una representación del mundo que los produce y de la cultura que se los apropia a modo de infundir lo que se debe leer y estudiar (Escolano en Álvarez-Sanchís y Ruiz, 1997; Bernstein en Samper, 1998; Escolano, 2009; Van Dijk en Fernández, 2010). Por lo demás, el texto se transforma en un material legítimo y amparado como correcto, es decir, con información real y fidedigna, al punto que, para apoderados, estudiantes, y muchas veces la sociedad en general, se ha convertido al texto en un medio per se con plena confianza en la educación formal (Schmidt en Ruiz y Vallejo, 1999; Ramírez, 2002; Vergara, 2008). Incluso, en términos foucaultianos, se podría extrapolar la noción de dispositivo y ajustarlo al contexto del texto escolar, ya que el dispositivo hace referencia "a una red de relaciones entre elementos heterogéneos (discursos, instituciones, arquitecturas, reglamentos, enunciados científicos, etc.), en la que el propio dispositivo establece la naturaleza del nexo de la red; nexo que liga a todos los elementos heterogéneos" (Hernando, 2015, p. 20). En este sentido, el manual sería una ejemplificación de aquella red de enlaces diversos que actúan de manera conjunta con el propósito de transmitir una postura ideológica particular.

Sin embargo, los textos escolares dependen del establecimiento del currículum nacional, el que, a su vez, deriva de los cánones políticos e ideológico de los gobiernos de turno. ¿Qué dice, en este caso, el currículum nacional en relación a la enseñanza de la prehistoria y la arqueología? 


\subsection{UNA MIRADA AL CURRÍCULUM NACIONAL}

Ningún discurso es neutro ni ingenuo, sobre todo cuando se construye como relato oficial. En este caso, el currículum nacional, como política educacional estatal, tiene una intención determinada que, como indica Vergara, "refleja la sociedad dominante y cómo ésta desea mirar su historia; dentro de este espacio de control, la educación es una pieza clave para llegar a los grupos de formación y construir así el imaginario de patria que se considera valioso" (2008, p. 269). En este caso, lo que interesa es esa forma en que se mira la historia o, en este caso, la prehistoria. Nuevamente está en la noción de presencia, en lo visible, "la selección de aquello que tiene pretensiones de ser visto y retenido, y todo lo omitido tendrá como idea invisibilizar las partes de la historia que no contribuirían a este imaginario que quiere plasmarse en los educandos" (Vergara, 2008, p. 269) como, por ejemplo, las mujeres prehistóricas.

De los tres pilares fundamentales del currículum educacional (Planes de Estudios, Programas de Estudio -PE- y Bases Curriculares -BC-), y para efectos de este estudio, se explicará brevemente los dos últimos. Los PE están destinados a cada asignatura, planteándose allí una propuesta didáctica de cómo apoyar el logro de la meta país definida en el currículum nacional, de manera tal que entregan una organización temporal de los Objetivos de Aprendizaje para su logro en cada año escolar, facilitando con esto el quehacer pedagógico en el aula. Específicamente, en su introducción sobre la asignatura de HGyCS, los PE mencionan que

esta asignatura está conformada por disciplinas que estudian al ser humano como individuo y como miembro de la sociedad desde diversas perspectivas, entre las que se incluyen, además de la Historia y la Geografía, la Economía, la Demografía, la Sociología y la Ciencia Política. (Programa de Estudio de HGyCS, 2016, p. 36)

También el documento versa que "el trabajo conjunto de estas disciplinas permite al estudiante desarrollar conocimientos, habilidades y actitudes necesarias para comprender la complejidad de la realidad social y el devenir de nuestra sociedad" (2016, p. 36). No hay ninguna mención, aunque sea redundante -por el caso de ser la asignatura en cuestiónsobre el pasado, estableciéndose, a su vez, la prioridad de comprender la realidad social y el devenir de nuestra sociedad. De este modo, mirar el presente y pensar el futuro; nada de reflexionar sobre el pasado. Así, difícil que la arqueología sea considerada y, con ella, la prehistoria y sus sujetos históricos a partir de nuevas investigaciones.

Por su parte, las BC indican cuáles deben ser los aprendizajes comunes para todos los y las estudiantes del país durante su trayectoria escolar. Específicamente, éstas mencionan que la asignatura de HGyCS está conformada por:

disciplinas que estudian desde diversas perspectivas al ser humano en el tiempo y en el espacio. El trabajo conjunto de estas disciplinas permite a la o el estudiante desarrollar conocimientos, habilidades y actitudes necesarias para comprender la complejidad de la realidad social y el devenir de nuestra sociedad (Bases Curriculares del Ministerio de Educación de Chile, 2016, p. 176).

El documento citado indica que la asignatura busca promover aprendizajes que representen un aporte significativo para enfrentar los desafíos de desenvolverse en un mundo cada vez más dinámico, plural y cambiante, de forma que contribuya a la 
formación de personas capaces de analizar realidades complejas y de desarrollar visiones propias fundadas en un pensamiento riguroso y crítico. Asimismo, personas con las herramientas para comprender mejor su presente, establecer conexiones con el pasado y trazar planes a futuro (Bases Curriculares del Ministerio de Educación de Chile, 2016, p. 176).

Es decir, se desprende una preocupación mayor por el presente y el devenir, más que una reflexión crítica y atenta sobre el pasado.

La pregunta que surge ahora es: ¿cómo se ha implantado en los últimos años el discurso sobre la prehistoria por medio de la enseñanza de los textos escolares en Chile?

\section{METODOLOGÍA Y MUESTRA}

\subsection{METODOLOGÍA}

Este estudio se enmarca en la investigación cualitativa, asociada con la exploración en profundidad de significados, las experiencias de las personas en su cotidianeidad, como en este caso son los estudiantes y los textos escolares en el marco de la educación reglada chilena. En palabras de Bautista, este tipo de investigación "conduce a dar respuestas y explicaciones sobre eventos y acontecimientos que, mediante el uso de una codificación lingüística y orden estructural, integre diversos elementos y datos (...) que permitan la apertura de establecer juicios y criterios" (2011, p. 18). A su vez, el paradigma empleado en este tipo de investigación es el interpretativo, de manera que se consiga aunar, en un marco teórico, los hallazgos, es decir, hacer permear los significados analizados en una explicación particular y no general, por cuanto la finalidad de este paradigma es comprender e interpretar la realidad, los significados de las personas, las percepciones, intenciones o acciones. Así, la investigación cualitativa aplicada en el ámbito educativo busca comprender la realidad para aplicar tanto mejoras como cambios y no quedarse sólo con la descripción de los fenómenos, sino profundizar sobre éstos y su explicación (Bisquerra, 2016, p. 26).

\subsection{MUESTRA}

A su vez, los textos estudiados, y por ende la muestra seleccionada, corresponde a los manuales de HGyC, de 7 mo básico, entre los años 2010 y 2018 (sin considerar el año 2011 por no contar, al momento del estudio, con tales documentos) que han sido distribuidos, gratuitamente por el Estado, en establecimientos municipales y particulares subvencionados. Se pretendió tal marco temporal que abarca casi una década para, así, no sólo coincidir con las últimas modificaciones y ajustes curriculares en la asignatura en cuestión, sino para observar diacrónicamente los cambios y las continuidades en la representación de las mujeres prehistóricas en la enseñanza escolar chilena. Es importante mencionar también que se han analizado los libros a partir de distintas editoriales, siendo aquellas: Mare Nostrum (2010 y 2012), Vicens Vives (2013) y SM Chile (dos versiones, 2014 al 2015 y 2016 al 2018). En este último caso, a pesar de ser la misma editorial, los contenidos, la presentación y los enfoques didácticos - por nombrar algunos aspectos- son diferentes en aquellos años y, por ende, clasificados y analizados de forma independiente en este estudio. 
Finalmente, sólo fueron considerados los textos de 7 mo básico ya que sólo en este nivel se realiza la enseñanza de la prehistoria universal.

\subsection{MODELO DE ANÁLISIS}

La prehistoria ha sido considerada como un terreno fértil para la participación de diversas ciencias sociales y disciplinas científicas, de manera tal que de sus intervenciones se ha creado un relato sobre el pasado histórico. Sin embargo, la lejanía temporal de la prehistoria también ha procurado su conversión en escenario ideal para la mitificación y la ficción, por lo que acudir a su estudio resulta tan necesario como interesante, a modo de reconocer en el discurso heredado tanto lo real como lo inventado. El objeto de estudio (prehistoria) como los sujetos de estudio (hombres y mujeres prehistóricos), según esta autora, han estado en permanente investigación a partir de las representaciones que se realizan de ellos, tanto en el relato literario como en la demostración figurativa, concretándose "una serie de rasgos comunes que tratan de forma diferencial a los humanos-hombres de los humanos-mujeres" (González, 2009, p. 93). Continuando con la autora recién citada, y específicamente en relación con las mujeres prehistóricas, indica que hay cuatro patrones de análisis que deben ser atendidos en cualquier material de divulgación de conocimiento prehistórico, aspectos que serán considerados a continuación en este estudio:

a) las características y capacidades biológicas de la especie humana se definen en relación al cuerpo masculino; b) el dominio de cierto tipo de tecnologías, adscritas actualmente a los hombres (y también en su proyección hacia el pasado remoto), se define como motor de la sociedad; c) el pensamiento abstracto, la capacidad de comunicación avanzada y, en general, la creatividad y la innovación se representan como cualidades eminentemente masculinas; d) las formas de vida en sociedad y sus transformaciones están organizadas y dirigidas principalmente por hombres (González, 2009, p. 93).

\section{ANÁLISIS Y DISCUSIÓN SOBRE LAS MUJERES PREHISTÓRICAS EN LOS TEXTOS ESTUDIADOS}

\subsection{CARACTERÍSTICAS Y CAPACIDADES BIOLÓGICAS}

La hominización es el mejor ejemplo para reflejar la adscripción de los sexos en la enseñanza de la prehistoria. Los textos escolares de 2010 y 2012 indicaban que "los representantes del género humano evolucionaron hasta alcanzar las características físicas de los seres humanos actuales", pero, pareciera ser que, en su concepción, los representantes del género humano debieran entenderse sólo los hombres de distintas especies en el largo camino de la hominización (imágenes 5, 6 y 7). 
Imagen 5: Ilustración de Hominización. Editorial Mare Nostrum, 2010-2012: 54-55.
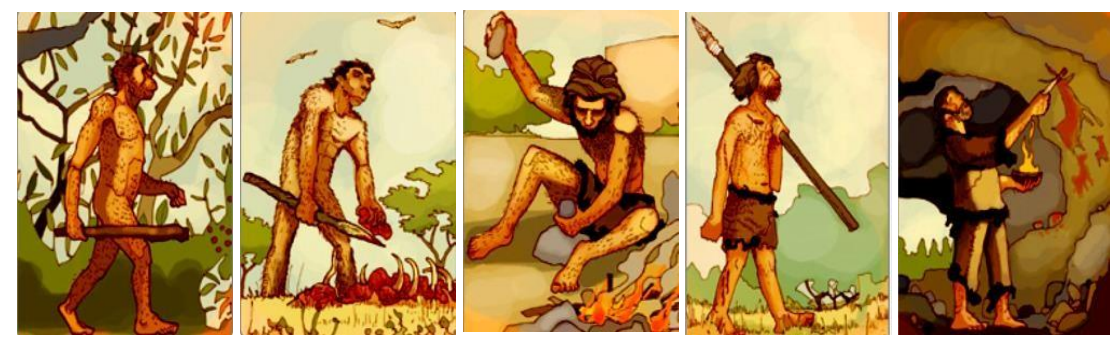

Imagen 6: Ilustración de Hominización. Editorial Vicens Vives, 2013: 70-71.

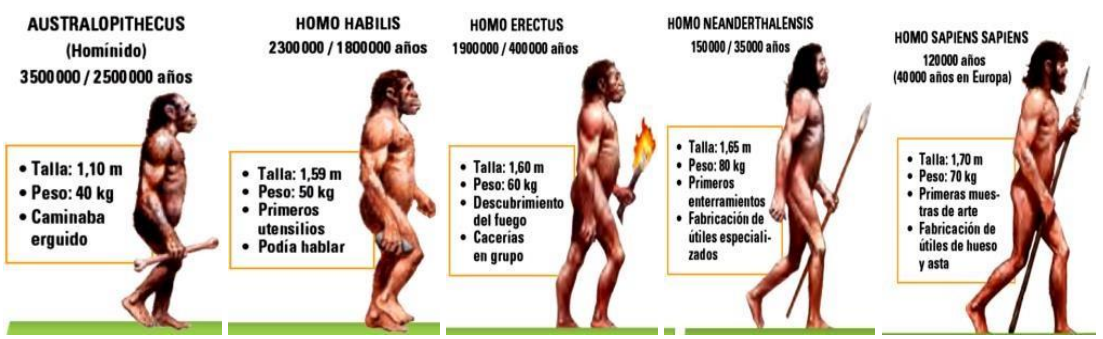

Imagen 7: Restos óseos e ilustración de Neanderthal. Editorial SM Chile, 2014-2015: 92-93.
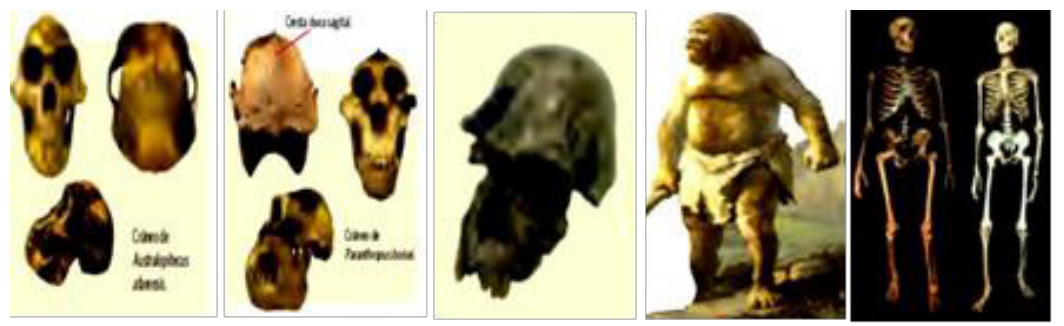

Imagen 8: Ilustración de Hominización. Editorial SM Chile, 2016-2018: 22-23.

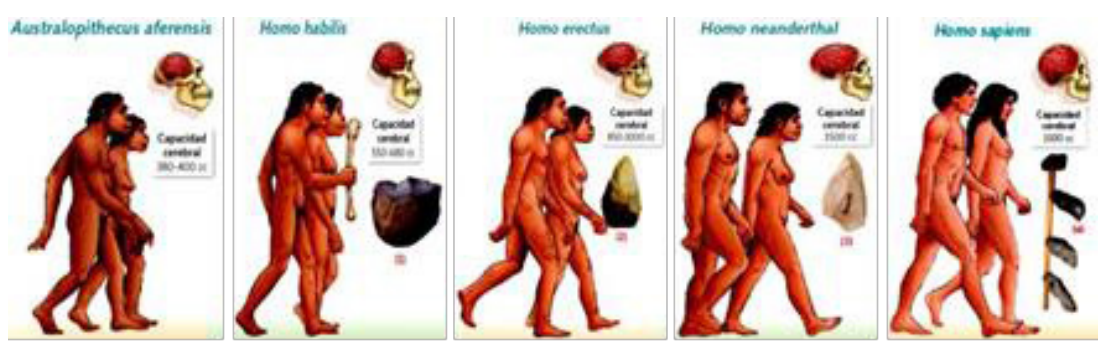


Iconográficamente, se observa la anulación de las mujeres como sujetos históricos, por lo que lo "humano" estaría protagonizado sólo por el hombre. El discurso figurativo y asociativo sobre hombre-objeto-progreso había estado presente sin grandes modificaciones hasta hace sólo dos años, cuando los textos escolares desde el 2016 incorporaron en la evolución homínida -aunque en un segundo plano- a la mujer (imagen 8). En cuanto a las populares imágenes sucesivas y representativas de la hominización, González nos dice que "nos muestran, no ya al hombre, sino a los genes masculinos como artífices biológicos de la evolución de nuestra especie” (González, 2009, p. 94). ¿Por qué si se incluye a la mujer no se la hace portadora de algún material o tecnología? Que el hombre mantenga el dominio de los instrumentos, ¿qué podría significar? ¿Poder, control, inteligencia, habilidad, ninguna de éstas o todas las anteriores? Junto con la absoluta presencia de ellos, se quiere transmitir como conocimiento formal a los estudiantes que fueron los hombres quienes realizaron la caza, el descubrimiento del fuego, la producción artística y, por ende, la mayoría de las prácticas asociadas al período paleolítico.

En alusión al discurso del paleolítico, los manuales de 2010 y 2012 señalan que "a partir de los restos arqueológicos y del estudio de sociedades recolectoras que aún existen, los investigadores se han aproximado a establecer la cultura o el estilo de vida de los grupos que vivieron a fines del paleolítico”. Sin embargo ¿qué grupos?, ¿qué fuentes se utilizan?, ¿por qué se alude a un pasado sin respaldo de fuentes?

Continuando con los primeros textos estudiados, se mencionaba en alusión al paleolítico que "eran sociedades recolectoras que obtenían sus alimentos fundamentales de la recolección, la pesca y la caza". El texto especificaba cada una de éstas de la siguiente manera: "la recolección era la actividad más recurrente y sencilla. Las mujeres y los niños salían a recoger frutos silvestres [...]" (cursivas nuestras). Por su parte, la pesca "podía ser realizada por hombres, mujeres y niños, excepto cuando se trataba de la captura de especies de mayor tamaño, tarea que se reservaba a los hombres adultos" (cursivas nuestras). Finalmente, "la caza puede ser considerada como una actividad fundamental (...) La caza era una tarea que realizaban los hombres adultos, quienes debían actuar en forma colectiva" (cursivas nuestras). De lo sencillo a lo fundamental, de lo recurrente a lo excepcional, de la mujer al hombre, esas eran las asociaciones deterministas, bajo un fuerte sesgo sexista, con las que se envestían los textos escolares de inicio de década.

En este mismo escenario, nos encontramos que en los manuales escolares de los años 2014 y 2015 se mencionaba que, en el paleolítico, "las labores cotidianas comenzaron a dividirse según el sexo y la edad. Así, por ejemplo, los hombres salían del campamento en búsqueda de presas (carne), mientras mujeres, niños y ancianos practicaban la recolección". ¿Cómo lo anterior puede ser contrastado científica e históricamente? El texto escolar de estos años no utiliza fuentes arqueológicas, etnográficas ni ninguna referencia documental. Estos mismos manuales, en referencia a la hominización, indican en relación al registro fósil que, "estos restos son fragmentarios y en muchos casos pueden ser interpretados de distintas maneras, por lo que las conclusiones suelen ser divergentes. Sin embargo, aun así, hay bastantes hechos e ideas en torno a las cuales la mayoría de los estudiosos están de acuerdo”. ¿El estudiantado debe entender que, entonces, las mujeres recolectaban y los hombres cazaban, sin prueba alguna y sólo porque el texto lo menciona porque, aparentemente, los estudiosos están de acuerdo?

Por su parte, y a diferencia de estos textos escolares, el texto del 2013 y los de 2016 a la fecha no aluden a funciones demarcadas sexualmente en el paleolítico. De hecho, en 
muchas oportunidades en el discurso se alude a que "los seres humanos", "el grupo", "la sociedad", realizaba tal o cual función. A pesar de esto, este trabajo colectivo, en el plano figurativo, no hace alusión a que todos compartían las mismas tareas, sino que laboraban como grupo, pero en funciones divididas por sexo. En otras palabras, lo que no dice el discurso textual lo dice el discurso figurativo. Es decir, de todos modos, se está enseñando aquello que se ha pretendido superar con los años.

Volviendo al estudio de los manuales de 2010 y 2012, una actividad que cierra la explicación del paleolítico refuerza lo que ya se ha venido explicando. La imagen 9 fue utilizada como actividad de clase y fue acompañada del siguiente cuestionario: debajo de ella se pregunta a los estudiantes “¿quiénes participaban de la recolección?”, “¿qué utensilio ocupaban y de qué material podía ser?", mientras que debajo de la imagen de los hombres se lee: “¿qué animal están cazando?”, “¿con qué arma?”, “¿con qué estrategia?” No se vuelve a preguntar por quiénes cazan ya que se naturaliza que es una actividad de hombres, mientras que se determinaba lo que hacían las mujeres.

Imagen 9.- "Las sociedades recolectoras de fines del Paleolítico".

Texto de HGyCS, 2010 y 2012, p. 59.

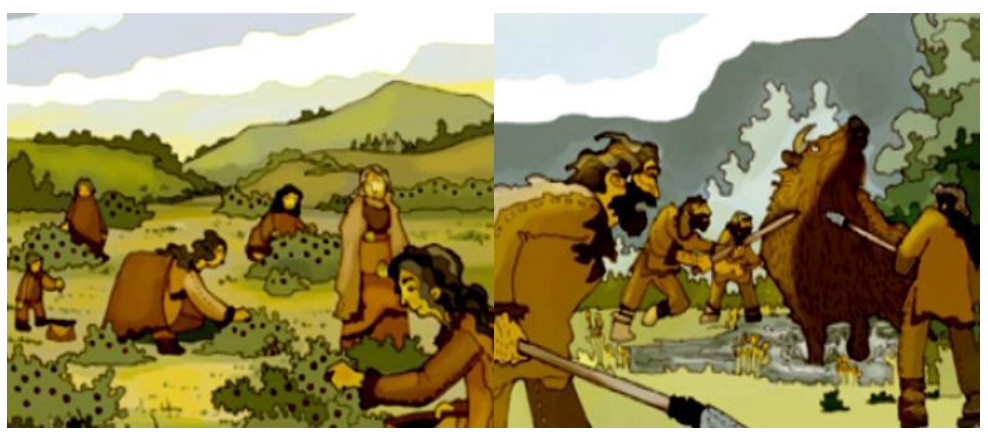

Con respecto al neolítico, los textos de los años 2010 y 2012 indicaban que las mujeres "participaban en la recolección de los cereales y los cocinaban. Observando el crecimiento de los vegetales y experimentando, deben haber comprobado que al enterrar granos y regarlos surgían nuevas plantas. Se descubría así el principio fundamental de la agricultura que se aplicó luego a otras especies" (cursivas nuestras). El texto hablaba de que debido al descubrimiento de la agricultura se había concretado una revolución, uno de los procesos más trascendentales de la historia, sin embargo ¿por qué no se asocia esta revolución a la mujer, si fue ella quien la habría propiciado? Quizá es porque "deben haber comprobado que al enterrar granos y regarlos surgían nuevas plantas", es decir, se estima, es probable, es un supuesto que pudieron haberlo realizado. Si es así, entonces, si no hay certezas en el origen del proceso de la domesticación de plantas, como a su vez en los actores que en un principio realizaron tales labores, ¿por qué no hay los mismos supuestos o, en otras palabras, no hay una apertura a la discusión, sobre actividades en la prehistoria que son directamente asociadas a los hombres? 
Los textos de los últimos tres años, en su discurso textual, son mayormente inclusivos sobre las labores en la prehistoria. Por ejemplo, se indica que "a lo largo de un lento y prolongado proceso de desarrollo técnico, los hombres y mujeres del paleolítico van perfeccionando el trabajo de la piedra tallada...", también indican que "si bien los restos materiales son escasos y existen distintas teorías sobre el estilo de vida de los homínidos del paleolítico, los especialistas por lo general están de acuerdo en algunas características: vivieron en bandas $[\ldots]$, eran nómadas [...], comenzaron a manejar el fuego [...] y construyeron refugios $[\ldots]$ ”.

Es decir, no hay ninguna asignación taxativa hacia una función a partir del sexo. A su vez, tampoco hay una asociación que determine que fueron las mujeres las que recolectaban granos silvestres que, por un motivo desconocido, comenzaron a domesticar, desprendiéndose de los textos de los años 2016 al 2018 lo siguiente: "tras el fin de la última glaciación [...], las capas de hielo que habían cubierto parte de la Tierra comenzaron a retroceder [...], iniciándose un largo período que culminará con la domesticación de plantas y animales [...]". No alude a mujeres, pero tampoco a hombres, produciéndose una deshumanización sobre el mismo proceso de domesticación, comunicándolo prácticamente como cambio natural en el planeta, como un corolario ajeno a la participación de la sociedad. Cumple con un propósito, el de no realizar un discurso sexista, pero se extrema al punto de desprender la domesticación de los alimentos como un acto humano, en el que solamente se describe, pero no se explica tal proceso.

\subsection{DOMINIO DE TECNOLOGÍAS}

Como se ha apreciado en las imágenes anteriores, la línea de hominización desde el Australopithecus hasta el Homo sapiens no sólo ha estado, casi invariablemente, protagonizada por el hombre, sino que, junto con ello, se le ha asociado con una herramienta. Ya fuese ésta para fines específicos de sobrevivencia o para producción en general, se ha vinculado al hombre la capacidad, desde el pasado más remoto, de ser él el creador de la tecnología, de ser él el portador de ella y, al fin de cuentas, de ser él el hacedor de la evolución humana. Palos, piedra tallada, fuego, arte rupestre y piedra pulida son los elementos asociativos de cada especie y de cada hombre representado en él (imágenes 5, 6 y 8).

Imagen 10.- Imagen de "las sociedades recolectoras de fines del Paleolítico". Texto de HGyCS, 2010 y 2012: 60.

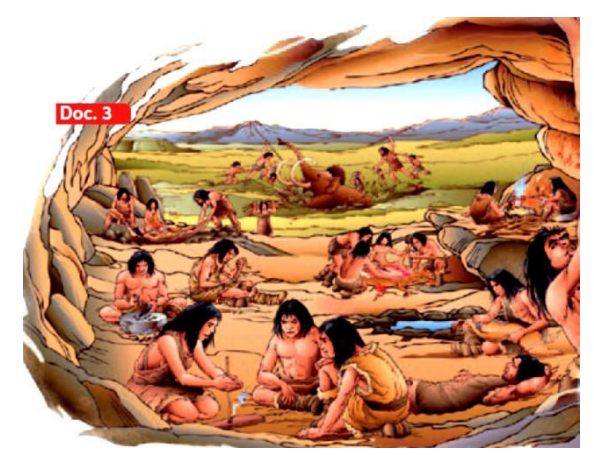


Imagen 11.- Imagen de la "vida cotidiana en el paleolítico".

Texto de HGyCS, 2016-2018: 29.

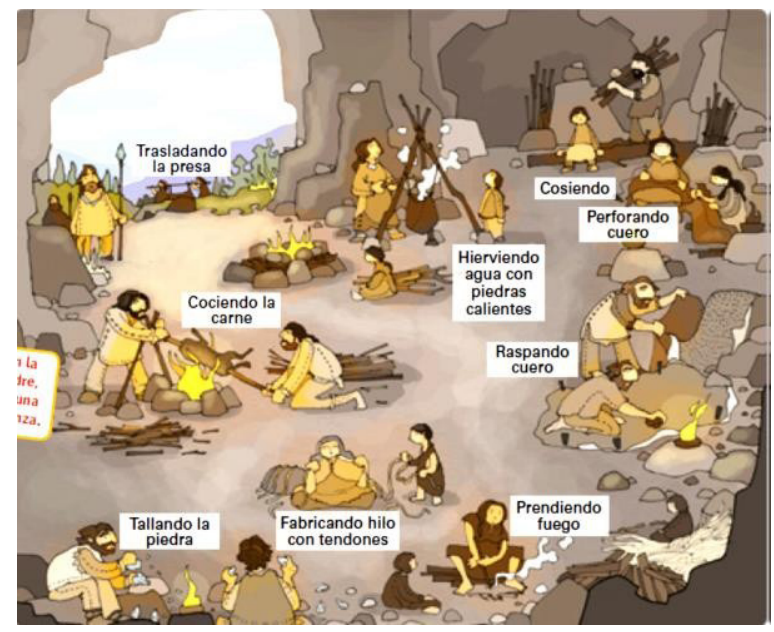

Es común hallar en textos escolares y manuales universitarios estudios sobre los más antiguos testimonios de la humanidad: los útiles de piedra llamados choppers, que cuentan con más de 1,5 millones de años de antigüedad (González, 2009, p. 94). Tal cual indica esta autora, "tradicionalmente estos choppers han sido considerados las primeras herramientas de factura humana documentada científicamente y, por ello, suponen, un punto de inflexión, por no decir el punto de inflexión en la larga marcha de los homínidos hasta los humanos" (González, 2009, p. 94). Con respecto a los textos escolares estudiados, todos se dedican a incorporar información sobre tecnologías: por ejemplo, punzones, raspadores, cuchillos y buriles (2010 y 2012); sobre el proceso de elaboración de bifaces, raspadores, puntas de lanza y perforadores (2013); sobre actividades relacionadas con herramientas de piedra hechas de piedra volcánica (2014 y 2015); y sobre el desarrollo tecnológico de la piedra en el paleolítico inferior, medio y superior (2016, 2017 y 2018). En el discurso escrito, no hay menciones sobre que era el hombre quien realizaba esta producción, no obstante, ¿qué enseñan las imágenes? Los únicos textos que hacen una representación que involucra estas actividades son los manuales de los años 2010 y 2012 (imagen 10) y del 2016 a 2018 (imagen 11), en donde se observa que, en todos los casos, son los hombres quienes realizan tales funciones. Es decir, habrían sido los hombres, en palabras de González, los que habrían hecho el punto de inflexión en la tecnología humana.

El pensamiento sobre la producción de la prehistoria ha recaído, indefectiblemente, en una "perspectiva exclusivamente tecnológica del cambio cultural, la que ha estado centrada sólo en el progreso de ciertas formas de utillaje que constituyen los elementos dominantes del registro arqueológico" (Masvidal y Picazo, 2005, p. 12). Por esto, y continuando con las autoras referenciadas, se debiera incluir, describir y explicar "la importancia de los sistemas de producción, por ejemplo, en lo que se refiere a las formas de obtención, transformación y distribución de los alimentos", demostrándose con ello "la importancia de las actividades y las prácticas de relación realizadas por las mujeres con otras mujeres 
o con los hombres del grupo" (Masvidal y Picazo, 2005, p. 12). Lo anterior recuerda lo mencionado sobre las actividades de mantenimiento, ante lo cual cabe preguntarse ¿los textos escolares conciben tales labores como actividades y prácticas de producción para la mantención y sobrevivencia de los grupos en la prehistoria? Sólo un caso: en los manuales de 2010 y 2012 se lee que "los enfermos y personas mayores tenían pocas posibilidades de subsistir", no encontrándose ninguna alusión a la curación, la atención o la producción de alimentación adecuada. Es decir, no existe la atención que se merecen las actividades de mantenimiento, tanto en su descripción como explicación, en los manuales escolares, lo que fomentaría un mejor estudio sobre las mujeres prehistóricas.

\subsection{PENSAMIENTO ABSTRACTO Y CAPACIDAD DE COMUNICACIÓN}

Resulta complejo determinar en arqueología si fueron hombres o mujeres, los que realizaron, por ejemplo, la caza o recolección. Sin embargo, los textos escolares remarcan constantemente las actividades hechas por unos y otros sin mayor respaldo. En este mismo plano, y continuando con el tercer punto de análisis, el pensamiento abstracto y capacidad de comunicación que nos ha llegado hasta nuestros días a partir del arte rupestre, no ha quedado exento de esta asociación infundada. De los manuales estudiados, salvo el de los años 2014- 2015 que no presenta figuración al respecto, todos relacionan la creación de figuras en las cuevas como una actividad de hombres (imágenes 12, 13 y 14). Las dos primeras imágenes ilustran a hombres dibujando y pintando animales, relación que se ha heredado históricamente al creer que al ser la caza una actividad masculina facultaba, por ende, mejores conocimientos empíricos para tales expresiones (Gombrich, 1999, p. 40 y ss).

La técnica del estarcido en las cuevas (imagen 14) es vinculado, sin tapujos, a los hombres. No obstante, en el año 2013, el arqueólogo Dean Snow publicó que, tras una investigación en los sitios rupestres del paleolítico superior de Francia y España, y en base a una relación algorítmica sobre el dimorfismo sexual en las manos de los hombres y las mujeres de por entonces, existe una alta probabilidad de considerar estas creaciones como un trabajo de mujeres, refutando la suposición tradicional de que las plantillas de la mano humano en el arte parietal europeo fueron hechas por hombres adultos o jóvenes (2006, p. 393 y ss). Si bien sus análisis requieren de otras comprobaciones, al menos se está proponiendo una lectura alternativa sobre el pasado.

El punto no es atribuir totalmente este arte a las mujeres, sino que, solamente, aportar a que las mujeres sí pudieron haber sido parte de estas labores. Es decir, estas expresiones pudieron haber sido hechas tanto por unos como por otras, pero ¿por qué se mantiene un conocimiento histórico y, a su vez, una enseñanza prehistórica, sobre que fueron hechas sólo por hombres?

¿Por qué debemos quedarnos con la duda, tal como Galeano, sobre las mujeres sólo en la narración literaria y no plasmarla en los documentos científicos o educacionales? 
Imagen 12.- Una pareja de hombres realizando arte rupestre. Texto de HGyCS, 2010 y 2012: 61.

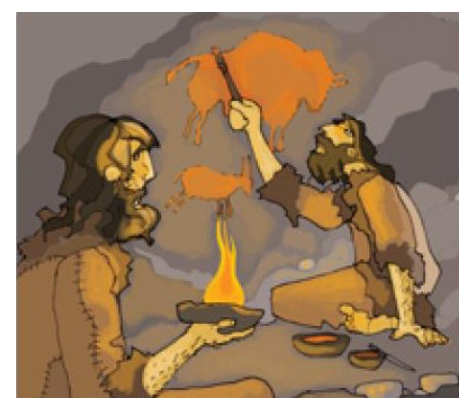

Imagen 13.- Un grupo de hombres realizando arte rupestre. Texto de HGyCS, 2013: 75.

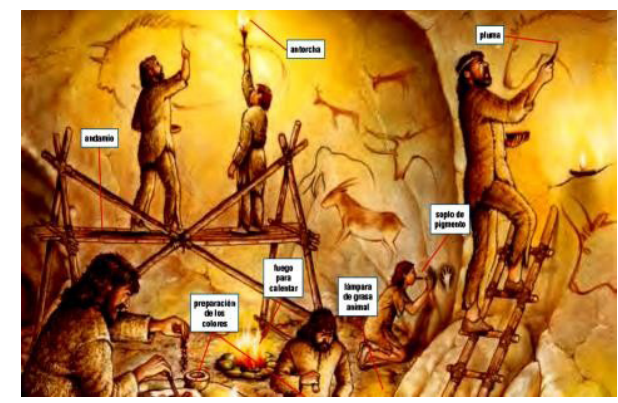

Imagen 14.- Un hombre continuando la técnica del estarcido. HGyCS, 2016-2018: 29.

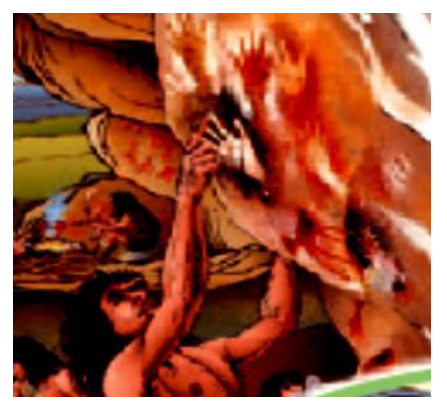

\subsection{FORMA DE VIDA EN SOCIEDAD}

Salvo la caza, la pesca y la recolección -como lo hemos visto ya en apartados anterioresel discurso de los textos escolares de los años 2010 y 2012 sobre el paleolítico no destaca otras funciones sociales. Sin embargo, la imagen que acompaña el relato sobre la vida 
cotidiana del paleolítico expresa mucho más que el discurso escrito (imagen 10). En esta imagen hay 22 individuos, de ellos se identifican 11 hombres (50\%), seis infantiles $(27,3 \%)$ (cuatro niños y dos niñas) y cinco mujeres $(22,7 \%)$. Los hombres cazan y trasladan la presa, cocen la carne, tallan la piedra, raspan el cuero y trasladan madera, mientras que las mujeres, junto a los infantiles, perforan el cuero, hierven el agua, prenden el fuego y fabrican hilo con tendones, es decir, funciones relacionadas con la vestimenta y la preparación de alimentos. Los infantiles aprenden con las mujeres y las ayudan, no siendo aquello similar con las labores supuestamente de hombres, los que estarían a cargo de todo el proceso de producción de herramientas, sobre todo elementos de caza. Salvo una, todo el resto de las mujeres se encuentra sentada haciendo su trabajo, a diferencia de los hombres, quienes realizan en su mayoría las labores de pie. Un caso peculiar es la pintura rupestre, desde la que no se asigna desde el discurso escrito una individualidad sexual, pero queda en evidencia que en larepresentación figurativa es el hombre el depositario de esta capacidad. Debajo de la imagen que alude a los hombres coloreando una figura animal, se indica "los pintores fabricaban con sustancias naturales y los impregnaban en la roca con pinceles [...]" (imagen 12).

Con respecto al análisis de los mismos textos de los años 2010 y 2012, pero en alusión a las sociedades neolíticas, ya se ha indicado con antelación que se relativizaba la inventiva de la agricultura, vinculando un supuesto accionar de la mujer con los granos silvestres. No obstante, no existe en los discursos de esos manuales ni supuestos referidos a etapas del paleolítico y, menos aún, supuestos vinculados a labores de hombres. En otro aspecto, al referirse a la revolución agrícola e indicar algunos de los múltiples aspectos que generó, llama la atención el siguiente: "la mortalidad se vio reducida con la mejor alimentación y con los beneficios de la vida sedentaria que permitió cuidar mejor a niños débiles a enfermos y ancianos". Nuevamente se está en presencia de una naturalización de la acción social (Soler, 2009, p. 116) y una deshumanización de un hecho relevante en la sobrevivencia de los grupos prehistóricos, ya que no se nombra a los agentes de las acciones, es decir, no se individualiza a los sujetos que realizan la sanación y poseen el conocimiento medicinal respectivo, sino que se da "por hecho" que se consiguió a raíz del establecimiento del sedentarismo y la agricultura.

Para finalizar con estos textos escolares, veamos la última representación figurativa en alusión al neolítico (imagen 15). Hay 21 personas realizando labores cotidianas, de ellas se identifican 10 hombres $(47,6 \%)$, ocho mujeres $(38,1)$ y tres infantiles $(14,3 \%)$, que son identificados como varones. Los hombres son relacionados con la cosecha, el arado, la recolección de agua, el abastecimiento de madera y la construcción del poblado, es decir, del control de los elementos básicos que transmite el discurso oficial para la supervivencia humana. Por su parte, las mujeres tejen, cocen el pan, hilan y confeccionan cerámica, es decir, están representadas bajo labores de alimentación y vestimenta. El discurso escolar declara textualmente todas éstas y otras actividades realizadas en el neolítico, pero lo hace de manera generalizada, aunque, como se ha visto, no ocurre del mismo modo en la representación figurativa.

En síntesis, existe en los textos de inicio de década una clara diferenciación sexual en la prehistoria, sobre todo en el discurso textual y figurativo del paleolítico. Por su parte, también hay una justificación del naturalismo por sobre el accionar humano, el que, en otras ocasiones dentro del discurso educativo, determina tajantemente lo que hicieron hombres y mujeres, sin mayores fundamentaciones. En relación al neolítico, no existe diferenciación 
sexual en el discurso escrito, sino más bien referencias generales a las labores realizadas, anulando la individualización que se aplicó en el período anterior. No obstante, esta equidad histórica no resulta similar en el ámbito figurativo, en donde se evidencia una clara separación de funciones por el sexo.

Imagen 15.- "La vida en un poblado neolítico".

Texto de HGyCS, 2010 y 2012: 64

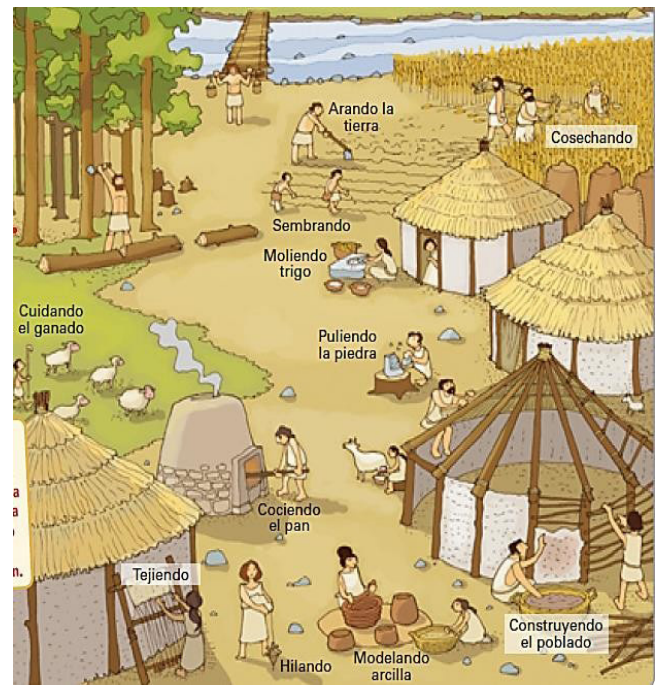

Por su parte, el manual del año 2013, en relación a la vida en el paleolítico, no individualizaba ninguna acción en su discurso textual, refiriéndose en todo momento a acciones colectivas. Por ejemplo, se indicaba que "los seres humanos tenían que recolectar frutos, pescar y cazar" o que "cazaban grandes mamíferos... aunque también atrapaban insectos, reptiles y pequeños mamíferos". Con respecto al fuego, se mencionaba que "el Homo erectus debió descubrir el fuego de forma casual... más adelante, los neandertales aprendieron a encender el fuego... el dominio del fuego fue un elemento muy importante en el progreso humano". Entonces ¿existía alguna preferencia en representar algún sexo en alguna labor paleolítica en el ámbito figurativo? De acuerdo con la imagen que acompaña la explicación del paleolítico en el texto del año 2013 (imagen 16), se puede decir lo siguiente: se encuentran 15 individuos en un primer plano y 10 en un segundo. Del primero se identifican 11 hombres (73,3\%), dos mujeres (13,3\%), un niño $(6,6 \%)$ y un individuo no identificado $(6,6 \%)$. Aun asumiendo que el sujeto que seca la carne del animal cazado es mujer, el porcentaje de representación femenina no llegaría al 20\%. En el segundo plano se identifican ocho hombres (80\%) y dos mujeres (20\%). En ambos planos se identifica que las labores de hombres se asocian a la caza de megafauna, fauna menor y aves, a la pesca, a la preparación de herramientas, al abastecimiento de madera y a la producción de fuego, al secado y raspaje de cuero, y al seccionamiento del animal cazado. Por su parte, las mujeres sanan heridas, ubican la carne para asar y recolectan. ¿Existe coherencia entre 
el relato escrito y su representación figurativa? No, la concentración de labores en hombres en el aspecto ilustrativo es muy grande. ¿Existe una consideración a una de las labores de mantenimiento de la sociedad que es la sanación de heridas y la sapiencia de la preparación de alimentación y las técnicas específicas para recolectar? No, sigue en evidencia que a comienzos de década no había una atención rigurosa sobre acciones sumamente relevantes en la prehistoria que significaron la sobrevivencia de los grupos.

Imagen 16.- "Un campamento paleolítico".

Texto de HGyCS, 2013: 73

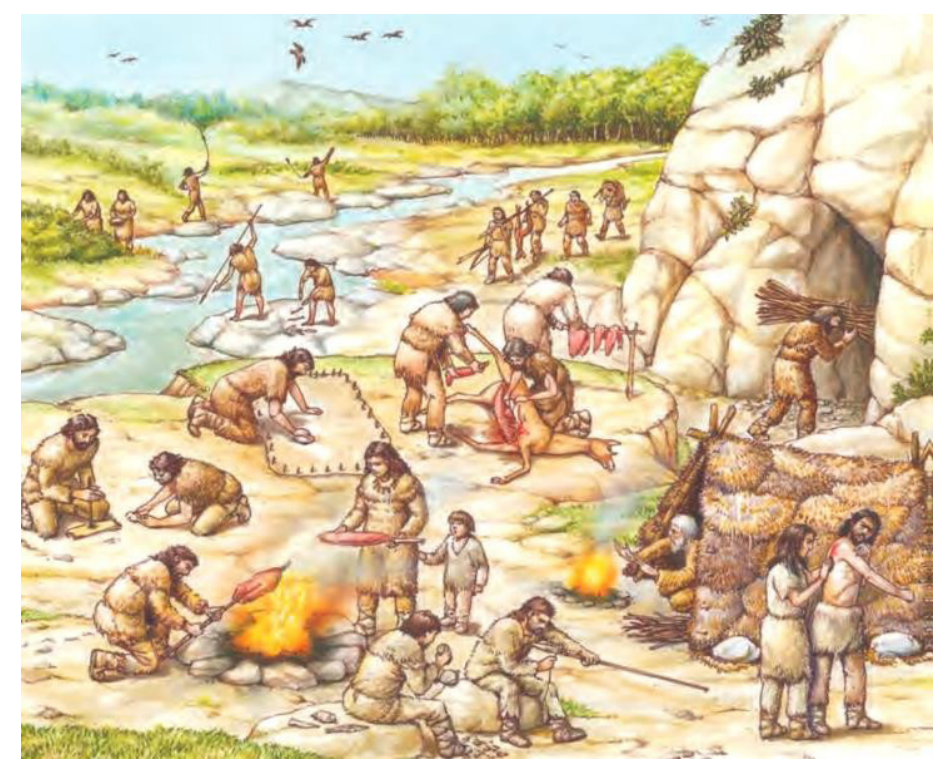

Con respecto al neolítico y la aparición de la agricultura y la ganadería, en este manual no se aludió al concepto de "revolución" tantas veces incluido en los textos de años previos. A su vez, menciona que "los hombres y las mujeres del neolítico aprendieron que las semillas enterradas bajo la tierra daban lugar a una nueva planta. Entonces, empezaron a cultivar cereales y legumbres... fue el origen de la agricultura". Junto con lo anterior, también el discurso textual apuntaba a que, con el aumento de alimento, hubo la necesidad de almacenar, transportar y cocer los alimentos, originándose el desarrollo de la cerámica (aspecto no mencionado por los textos antes estudiados). En esta ocasión, se indicaba que "hombres y mujeres empezaron a modelar barro y a cocerlo a elevadas temperaturas para endurecerlo". Todo lo anterior, y esta aparente simetría en la distribución de labores, ¿es coherente con la representación figurativa? En la imagen 17, que refleja la cotidianidad en la aldea neolítica de Çatal Hüyük, se observa -a pesar de su extensa cantidad de detallesque son los hombres los encargados de las actividades tradicionalmente denominadas como relevantes en la antigüedad. 
Imagen 17.- "La aldea neolítica de Çatal Hüyük".

Texto de HGyCS, 2013: 79

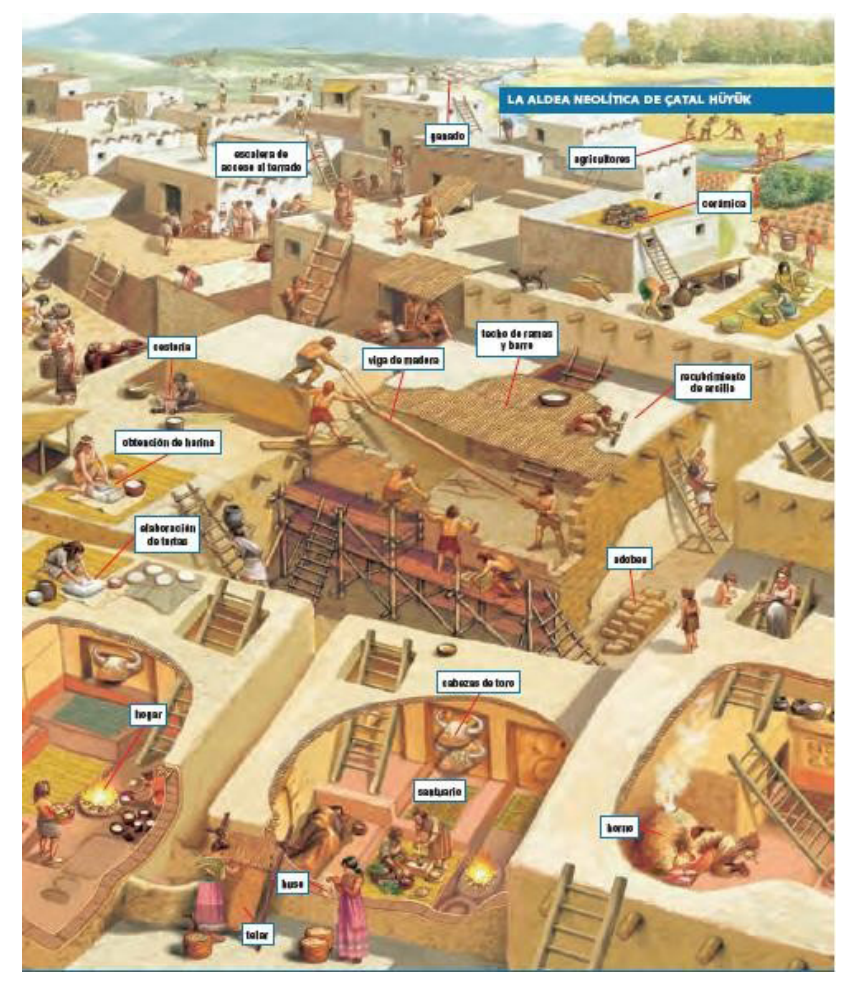

Con respecto al libro de texto de los años 2014 y 2015, y a diferencia de los anteriores manuales analizados, éste no presenta figuración alguna sobre la forma de vida en sociedad en el paleolítico. En relación al neolítico, tampoco hay acompañamiento de representación figurativa-evidenciándose, a su vez, las carencias didácticas y metodológicas de este manual escolar-, por lo que sólo hay comentarios como: "el ser humano desarrolló trascendentales avances en el dominio de un entorno que se volvía más cálido", "tras ese descubrimiento -la agricultura-, el ser humano se convirtió en agricultor y comenzó a asentarse en poblados...", "los grupos talaron bosques", "además de cultivar cereales y otros vegetales, en esta época el ser humano comenzó a domesticar animales". Es decir, a partir de la expresión "ser humano" se pretendió ocupar un lenguaje inclusivo y, así, no determinar funciones labores a partir del sexo. Sin embargo, su destacada intención de no sexualizar el pasado a partir de una determinación literaria sesgada no es suficiente para demostrar una representación más actualizada sobre los sujetos históricos de la prehistoria.

Finalmente, los textos de los años 2016 a 2018 no presentan un lenguaje diferenciador para labores hechas por hombres o por mujeres en el paleolítico, lo que no se corresponde, a su vez, con la representación figurativa de la que ya hemos hecho alusión anteriormente (imagen 11), en donde destaca la presencia y la actividad de los hombres. En correspondencia con la explicación del neolítico, estos manuales expresan que "se produjeron grandes 
transformaciones en la vida del ser humano por lo que algunos hablan de una revolución" o "uno de los principales cambios tras la radical transformación en la relación que los seres humanos tenían con el espacio geográfico fue la sedentarización”. No obstante, ¿esta neutralidad lingüística para referirse a las actividades realizadas en la prehistoria sería similar en la representación figurativa? La imagen 18 indica lo siguiente: de un total de 34 personas, 14 son hombres adultos $(41,2 \%), 14$ mujeres adultas $(41,2 \%)$, tres son infantiles $(8,8 \%)$ y tres no han sido identificados $(8,8 \%)$. Los hombres realizan la recolección de agua, cosechan, funden el metal, construyen herramientas, pastorean, navegan y cazan; mientras que las mujeres siembran y aran, realizan cerámica, muelen granos, tejen e hilan, siendo en casi todas estas actividades representadas de manera agachada, sentada o encuclillada, a diferencia de la imagen proyectada por los hombres. Es decir, como ha sido la tónica general, existe en los manuales de los últimos años una tendencia a incluir un lenguaje no sexista en los discursos textuales, aludiendo a actividades prehistóricas colectivas y generalizadas; sin embargo, a la hora de enfrentar lo escrito con lo figurativo, se aprecia una constante supremacía de individuos hombres que realizan actividades que han sido consideradas, tradicionalmente, como fundamentales para el desarrollo de la humanidad.

Imagen 18.- "Representación de un poblado neolítico". Texto de HGyCS, 2016-2018: 35.

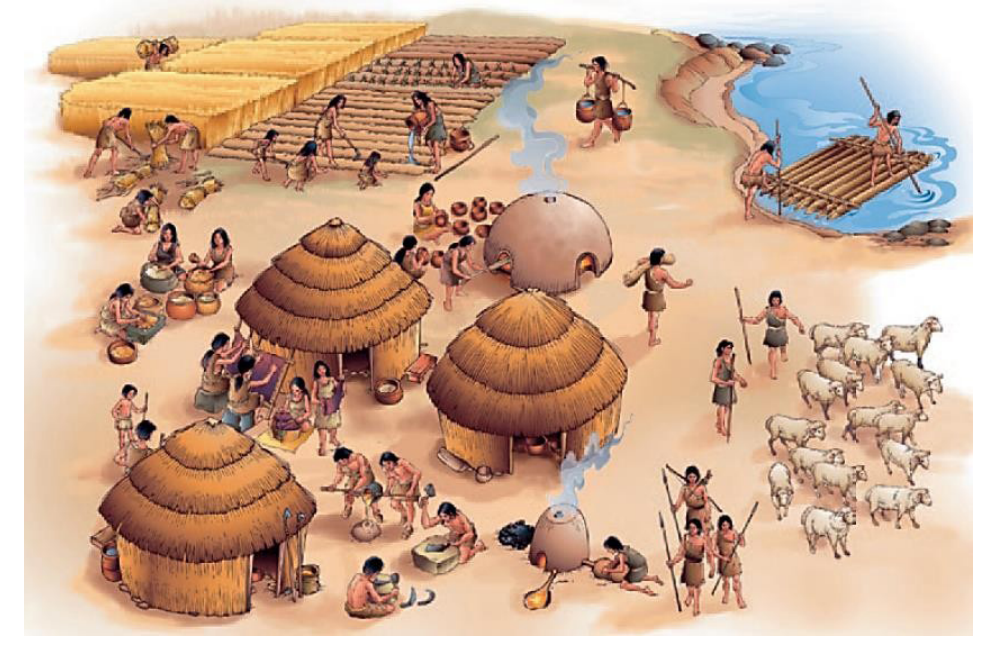

\section{PALABRAS DE CIERRE}

Si alguien preguntase ¿es realmente adecuado atender al estudio de la prehistoria para acabar de entender la realidad actual?, habría que responderle que, y siguiendo en esto a González, desde que surgió en el decimonónico la prehistoria en cuanto campo de investigación, "nuestra cultura la concibe como el lugar de nuestros orígenes que explica y, frecuentemente, justifica ciertos comportamientos actuales" (2009, p. 92). Es decir, el hecho de estudiar la prehistoria -y la forma en que ésta se enseña- es un aspecto crucial a la hora de poder aproximarnos al entendimiento que en la actualidad existe sobre la 
sociedad del ayer. La prehistoria, en cuanto contexto histórico, y la arqueología, como vía de acceso y conjunto de conocimientos adecuados para acceder a dicha cronología, deben ser necesariamente vinculadas y actualizadas en la educación de los estudiantes: no sólo por las múltiples ventajas formativas que ello implica, sino como forma de replantear el discurso histórico que se ha heredado como verdad irrefutable. En este sentido, se requiere tanto de la participación activa de la academia - siendo la Universidad su centro más importante- y la actualización de todos los agentes educativos para ejecutar de una mejor transmisión de los conocimientos. Así, es urgente que tanto el currículum educacional de Chile, como a su vez, las propuestas didácticas, metodológicas y pedagógicas de los manuales escolares se aúnen bajo criterios modernizados y fundamentados en cuanto a las explicaciones del período de la humanidad más lejano.

Un ejemplo de este discurso histórico heredado se ha visto a partir de la representación que se ha hecho de las mujeres en la prehistoria. Según se ha visto, la arqueología patriarcal academicista y luego transmitida, en este caso, en el formato de texto escolar, ha excluido, invisibilizado, ocultado y desatendido no sólo a las mujeres, sino a las labores vinculadas con ellas en la prehistoria, desestimando actividades que han permitido la continuidad de la vida social, la producción, la reproducción de objetos y sujetos y, por ende, de la formación y transformación de la sociedad. Como indican Masvidal y Picazo, "la situación de las mujeres en una determinada sociedad puede o no haber sido de subordinación, pero en cualquier caso ha sido consecuencia de procesos históricos determinados y en ningún caso "naturales" e "inevitables" (2005, p. 12), de modo que también sería pertinente "romper con los estereotipos sexistas en que se basa la comprensión del pasado. Las viejas identificaciones como la dicotomía entre la mujer recolectora y el hombre cazador; la división de tarea entre sexos como primera división del trabajo, naturalmente justificada [...]" (AA. VV. En Briz i Godino y Vietri, 2012, p. 975). Como indican estos últimos autores citados, hay que acabar con "la falsificación del pasado, mostrándolo como el precedente lógico de nuestro presente y justificándolo" (2012, p. 975). En esta importancia de sexuar el pasado no sólo se estaría identificando fehacientemente a los sujetos del pasado prehistórico en sus quehaceres sociales, sino que se estaría analizando el tipo de relación que existía entre estos dos colectivos (de la Torre y Lapi, 2014, p. 57).

Finalmente, en este contexto del estudio sobre las mujeres prehistóricas, se podría citar a Lozano y Montón, en cuanto indican que "el potencial de los discursos alternativos sobre el pasado se quedará a medias si quienes lo proponen no llevan su reflexión sobre los seres humanos del pasado a las prácticas de los seres humanos del presente" (2012, p. 170). Y una de estas prácticas del presente sobre los seres humanos del pasado es a través del estudio de los textos escolares, en este caso, sobre los discursos y la iconografía, particularmente, de las mujeres prehistóricas.

\section{REFERENCIAS BIBLIOGRÁFICAS}

Abril, D. y Cuenca, J. (2016). Prehistoria y Arqueología en $1^{\text {o }}$ de ESO: análisis documental y propuesta didáctica para la explicación de la organización social pasada y actual. Clío, History and History teaching, (42), 1-33.

Alarcón, E. (2010). Arqueología de las actividades de mantenimiento: un nuevo concepto en los estudios de las mujeres en el pasado. @rqueología y Territorio, (7), 195-210. Última visita 
22 de diciembre de 2018. Recuperado desde https://www.ugr.es/ arqueologyterritorio/PDF7/ Alarcon.pdf

Álvarez-Sanchís, J. y Ruiz, G. (1997). Prehistoria, texto e imagen. El pasado en los manuales escolares. Arx, (2), 149-164. Última visita 10 de diciembre de 2018. Recuperado desde http:// www.laiesken.net/arxjournal/pdf/zapatero.pdf

Bases Curriculares de $7^{\circ}$ básico a $2^{\circ}$ medio. Ministerio de Educación, Chile (2016).

Bautista, N. (2011). Proceso de la investigación cualitativa. Epistemología, metodología y aplicaciones. Bogotá: Manual Moderno.

Bayón, C., Pupio, A. y Simón, C. (2009). La construcción de la imagen de la arqueología como ciencia y sus profesionales en los discursos escolares. Actas de la III Jornadas de Investigación en Humanidades, 281-286.

Bisquerra, R. (2016). Metodología de la investigación educativa. Madrid: La Muralla.

Burke, P. (ed.) (1996). Formas de hacer Historia. Madrid: Alianza.

Briz i Godino, I. y Vietri, L. (2012). Arqueología Social Latinoamericana y Arqueología de las Mujeres: un encaje incompleto. Quaderni di Thule. Rivista d'Americanistica, (11), 969-980. Última visita 15 de diciembre de 2018. Recuperado desde https://www.researchgate.net/publication/275652437_ Arqueologia_Social_Latinoamerican a_y_Arqueologia_de_las_Mujeres_un_encaje_incompleto Davis, A. (2005). Mujeres, raza y clase. Madrid: Akal.

de la Torre, J. y Lapi, B. (2014). ¿Dónde están las mujeres?: reflexiones desde la arqueología peruana. Revista de Investigaciones del Centro de Estudiantes de Arqueología, (8), 47-62. Última visita 22 de noviembre de 2018. Recuperado desde https://www.academia.edu/15171917/_D\%C3\%B3nde_ est\%C3\%A1n_las_mujeres_Reflexiones_desde_la_Arqueolog\%C3\%ADa_Peruana

Escolano, A. (2009). El manual escolar y la cultura profesional de los docentes. Tendencias Pedagógicas, (14), 169-181.

Eyzaguirre, B. y Fontaine, L. (1997). El futuro en riesgo: nuestros textos escolares. Estudios Públicos, (68), 339-354. Última visita: 10 de diciembre de 2018. Recuperado desde https://www.cepchile. cl/cep/site/artic/20160303/asocfile/20160303184453/rev68_eyzaguirrefontai.pdf

Fernández, M. (2010). Las mujeres en el discurso pedagógico de la Historia. Exclusiones, silencios y olvidos. Revista Universum, 1(25), 85-99.

Flecha, C. (2004). Las mujeres en la historia de la educación. XXI Revista de Educación, (6), 21-34.

Galeano, E. (2008). Espejos. Una historia casi universal. Madrid: Siglo XXI.

Gombrich, E. (1999). Historia del Arte. México D. F.: Diana.

González, P. (2006). Mujeres y Prehistoria: vivir el presente, pensar el pasado. En B. Soler (Coord.), Las mujeres en la Prehistoria (pp. 15-26). Valencia: Museo Prehistórico de Valencia. (2009). La otra prehistoria: creación de imágenes en la literatura científica y divulgativa. En

C. Martínez y M. Nash (dirs.), Imágenes de mujeres de la Prehistoria (91- 109). Granada: Arenal. (2012). La dimensión educativa de la prehistoria y la arqueología. ler Congreso de Prehistoria de Andalucía: La tutela del patrimonio histórico, 1-20.

Gordones, G. (2008). ¿Arqueología para qué? Reflexiones sobre el conocimiento arqueológico en el ámbito educativo venezolano. Boletín Antropológico, 26(72), 7-24.

Hernando, A. (ed.) (2015). Mujeres, hombres, poder. Subjetividades en conflicto. Madrid: Traficantes de sueños.

Lewkowicz, M. y Rodríguez, M. (2015). Las sociedades aborígenes en los textos escolares: de "indios salvajes" a "pueblos originarios". Una mirada en la larga duración. Clío \& Asociados, (20), 116-137.

López, F. (2000). La arqueología en la educación secundaria. Innovación Educativa, (10), 343-352.

Lozano, S. (2011). El hombre es la medida de todas las cosas. El tópico androcéntrico en Arqueología y las alternativas metodológicas feministas. Estrat Crític, 3(5), 18-29.

Lozano, S. y Montón, S. (2012). La arqueología feminista en la normatividad académica. Complutum, 23(2), 163-176. 
Masvidal, C. y Picazo, M. (2005). Modelando la figura humana: reflexiones en torno a las imágenes femeninas de la antigüedad. Barcelona: Quaderns Crema.

Montón, S. (2014). Arqueologías Engeneradas. Breve introducción a los estudios de género en Arqueología hasta la actualidad. ArqueoWeb, (15), 242-247.

Programa de Estudio de Historia, Geografía y Ciencias Sociales. 7mo básico. Ministerio de Educación, Chile (2016).

Ramírez, T. (2002). El texto escolar como objeto de reflexión e investigación. Docencia Universitaria, $3(1), 101-124$.

Romero, F. y Sanz, C. (2009). Tiempo y género a partir de la Arqueología. Las necrópolis de Pintia (Padilla de Duero/Peñafiel, Valladolid). En AA. VV (Ed.), Protagonistas del pasado. Las mujeres desde la Prehistoria al siglo XX (59-203). Valladolid: Castilla Ediciones.

Ruiz, L. y Vallejo, C. (1999). ¿Qué queda del sexismo en los libros de texto? Revista Complutense de Educación, 10(2), 125-145.

Samper, L. (1998). Las desigualdades en el currículum de Ciencias Sociales. Género, etnia y estatus social. Actas del IX Simposio de Didáctica de las Ciencias Sociales, 69-74.

Sánchez, O. (2000). Algunas reflexiones para la prehistoria y arqueología: las mujeres en la construcción de la historia. SPAL, (9), 495-505.

Scott, J. (1996). Historia de las mujeres. En P. Burke (Ed.), Formas de hacer Historia (59- 88). Madrid: Alianza.

Snow, D. (2006). Sexual dimorphism in Upper Palaeolithic hand stencils. Antiquity, (80), 390-404.

Soler, S. (2009). La escuela y sus discursos. Los textos escolares como instrumentos de exclusión y segregación. Sociedad y Discurso, (15), 107-124.

Textos de Historia, Geografía y Ciencias Sociales. Editorial Mare Nostrum (2010 y 2012). Texto de Historia, Geografía y Ciencias Sociales. Editorial Vicens Vives (2013).

Textos de Historia, Geografía y Ciencias Sociales. Editorial SM Chile (2014 y 2015).

Textos de Historia, Geografía y Ciencias Sociales. Editorial SM Chile (2016, 2017 y 2018). Vergara, D. (2008). La identidad como objetivo transversal de los procesos cognitivos: aportes de la arqueología y de la elaboración de textos escolares en Chile. Cuadernos del Pensamiento Latinoamericano, (17), 266-285.

Vila, A. (2011). Política y feminismo en arqueología prehistórica. Revista Atlántica-Mediterránea, (13), 17-32.

Zurro, D. (2011). El suelo de cristal: la necesidad de visibilización para una arqueología feminista. Revista Atlántica-Mediterránea, (13), 65-80. 
